\title{
Dendritic Cell Vaccines in Ovarian Cancer
}

\author{
Xi Zhang ${ }^{1 \neq}$, Tianhui He ${ }^{1+\neq}$, Yuan $\mathrm{Li}^{1}$, Ling Chen ${ }^{2}$, Hongyu $\mathrm{Liu}^{3}$, Yu Wu ${ }^{1}$ \\ and Hongyan Guo ${ }^{1 *}$
}

${ }^{1}$ Department of OB/GYN, Peking University Third Hospital, Beijing, China, ${ }^{2}$ Department of Neurosurgery, First Medical Center of Chinese PLA General Hospital, Beijing, China, ${ }^{3}$ Department of Neurosurgery, Hainan Hospital of Chinese PLA General Hospital, Sanya, China

\section{OPEN ACCESS}

Edited by:

Silvia Sánchez-Ramón,

Complutense University of Madrid,

Spain

Reviewed by:

Georg Varga,

University Hospital Muenster,

Germany

Michal Amit Rahat,

Technion-Israel Institute of

Technology, Israel

${ }^{*}$ Correspondence:

Hongyan Guo

bysyghy@163.com

tORCID:

Tianhui He

orcid.org/0000000228350702

${ }^{\text {F}}$ These authors have contributed equally to this work and share first authorship

Specialty section:

This article was submitted to

Vaccines and

Molecular Therapeutics,

a section of the journal

Frontiers in Immunology

Received: 03 October 2020

Accepted: 04 December 2020

Published: 25 January 2021

Citation:

Zhang X, He T, Li Y, Chen L, LiU H, Wu Y and Guo H (2021) Dendritic Cell Vaccines in Ovarian Cancer. Front. Immunol. 11:613773. doi: 10.3389/fimmu.2020.613773
Ovarian cancer $(\mathrm{OC})$ is one of the most lethal malignant gynecologic tumors, characterized by an uncertain presentation and poor outcomes. With or without neoadjuvant chemotherapy, surgery followed by platinum-based chemotherapy and maintenance therapy are the basis for the treatment of ovarian cancer patients, but the outcome is still highly restricted by their advanced stage when diagnosed and high recurrence rate after chemotherapy. To enhance the anti-tumor effect and postpone recurrence, antiVEGF agents and PARP inhibitors are suggested as maintenance therapy, but the population that can benefit from these treatments is small. Based on the interactions of immune cells in the tumor microenvironment, immunotherapies are being explored for ovarian cancer treatment. Disappointingly, the immune checkpoint inhibitors show relatively low responses in ovarian cancer. As shown in several studies that have uncovered a relationship between DC infiltration and outcome in ovarian cancer patients, dendritic cell (DC)-based treatments might have a potential effect on ovarian cancer. In this review, we summarize the functions of dendritic cells (DCs) in the tumor microenvironment, as well as the responses and drawbacks of existing clinical studies to draw a comprehensive picture of DC vaccine treatment in ovarian cancer and to discuss the promising future of immune biomarkers.

Keywords: dendritic cells (DCs), ovarian cancer (OC), immunotherapy, tumor microenvironment, dendritic cell vaccine

\section{INTRODUCTION}

Ovarian cancer is the most lethal gynecological cancer, with an overall 5-year-survival rate of $48 \%$ (US, reported in 2020). Nearly 75\% of patients have no symptoms until an advanced stage, which leads to a $29 \%$ 5-year-survival (1). First-line treatments include surgery and platinum-based chemotherapy. Although primary treatments show remission effects, approximately $75 \%$ of patients suffer from recurrences, followed by eventual drug resistance state.

When confronted with recurrences, platinum-sensitive patients are recommended to accept platinum-based combined chemotherapy followed by targeted therapy according to the NCCN guidance. However, platinum-resistant recurrences have limited effective strategies to choose. The response rates to cytotoxic therapy [ex. topotecan, 20\% (2); docetaxel, $22 \%$ (3)] and single agents targeted therapy [ex. bevacizumab, 20\% (4)] are low, and furthermore, a combination of chemotherapy and bevacizumab increase the median overall survival by only 3.3 months, with 
no significant difference between the combination therapy and chemotherapy groups (5). Consequently, studies have focused on maintenance therapy to postpone any recurrence (6). Poly ADPribose polymerase (PARP) inhibitors, including olaparib, niraparib, and rucaparib, have manifested inspiring efficacy in maintenance therapy. Olaparib for those with BRCA1/2 mutations has increased the response rate to $36 \%$ (7), however, BRCA1/2 mutations exist in only $10 \%$ of ovarian cancer patients. Although niraparib and rucaparib extend their indications to those with homogenous repair deficiency (HRD) (8) as well as those with platinum-sensitive recurrent epithelial ovarian cancer (EOC) regardless of BRCA status (9), most patients still do not qualify. Emerging studies aim to elongate recurrence intervals for better survival, and immunotherapy is being considered.

The presence of tumor infiltration lymphocytes is related to a higher 5-year-survival rate ( $38 \%$ vs $4.5 \%$ ) in ovarian cancer (10), which throws light on immunotherapy. However, the efficacy of immune checkpoint blockers, such as the anti-PD-1 agent pembrolizumab, depend on microsatellite instability-high or mismatch repair-deficient circumstances. The overall response rate to pembrolizumab among $\mathrm{PD}-\mathrm{L}^{+}$advanced metastatic ovarian cancer patients is only $11.5 \%$ (11), and the percentage of $\mathrm{PD}-\mathrm{L1}^{+}$cases of high grade serous ovarian cancer is only $57.4 \%$, and it is $0 \%-26.7 \%$ in other histologic subtypes of ovarian cancer (12). Moreover, adoptive T cell therapy is hindered by a low level of T cell infiltration, poor neoantigen presenting function and immunological tolerance epitopes (6), which suggests to enhance the process of antigen-presenting for amplifying anti-tumor effect.

In the tumor microenvironment, dendritic cells take and process tumor-associated antigens, then present them by $\mathrm{MHCI} / \mathrm{II}$ molecules to activate $\mathrm{T}$ cells. With the aim of enhancing the process of antigen-presenting, DCs are regarded as promising target. The first clinical trial of dendritic cell (DC) vaccine started in 1996. Currently, more than 400 clinical trials of DC-based treatment for tumors have been registered in ClinicalTrials.gov. Up till June 2014, DC-based treatment in only four tumor types had reached phase III clinical trials, including melanoma, prostate cancer, malignant glioma and renal cell cancer (13). During 2014-2017, 43 peer-reviewed publications reported the outcomes of clinical trials on DC vaccines (14) in various cancers. In most clinical trials, some of the patients reached a stable state, and a lower percentage of patients reached a partial response or a complete response (according to RECIST guidelines). During 2017-2019, 34 peerreviewed papers were published (15) suggesting more strategies to improve the response rate to $\mathrm{DC}$ vaccines.

Safety was confirmed in most clinical trials and the response rate to DC-based treatment gradually increased due to improved production strategies. Antigen loading, DC origination and induced maturation strategies are key steps to produce DC vaccines, which stand at the core stage of innovation. In 2010, Sipuleucel-T became the first DC vaccine approved by the FDA, for the treatment of metastatic prostate cancer. In ovarian cancer, various DC vaccines have been tested, showed an increment in progression-free survival (PFS) and overall survival (OS) (16, 17), which inspired further studies.

\section{DIFFERENTIATION, MATURATION, AND FUNCTION OF THE DENDRITIC CELLS}

DCs originate from $\mathrm{CD} 34^{+}$hemopoietic stem cells in the bone, differentiate to different subtypes in the peripheral blood and nonlymphoid organs and tissues, and mature in the lymphoid organs (18-21) (Figure 1). Immature DCs that express low levels of toll-like receptors (TLRs) MHC molecules, costimulatory molecules, as well as adhesion molecules stay outside of lymphoid tissues and have weak antigen-presenting functions. TLRs are the essential receptors among the sensors of pathogenassociated molecular patterns (PAMPs) and damage associated molecular patterns (DAMPs). PAMPs from bacteria, viruses, or parasites activate DCs to activate the innate immune response (22), which act as a general defense against infectious diseases; in tumors, DCs are activated in response to DAMPs from tumor cells through TLR signaling (23).

The migration of immature DC is induced by the chemokine receptor CCR7 and CCR8, which is up-regulated during the maturation process (24). Stimulated by antigens, immature DCs migrate toward chemokine ligands CCL19 and CCL21 into lymph nodes and gradually develop into a mature state, highly expressing MHC I molecules, MHC II molecules, costimulatory molecules and adhesion molecules (25), then mature DCs active $\mathrm{CD}^{+} \mathrm{T}$ cells and $\mathrm{CD} 8^{+} \mathrm{T}$ cells at the tumor site migrate to lymphoid organs to build immune memory.

As robust antigen-presenting cells, DCs exert a key influence in regulating the innate immune response and initiating adaptive immune responses. DCs have more vigorous capability to capture, process and present antigens than other APCs, such as B cells, mononuclear cells, and macrophages (26). DCs take parts in forming the first and second signals to activate $\mathrm{T}$ cells. In the process of activating specific $\mathrm{T}$ cells, the MHC-antigen peptideTCR complexes act as the first signal, and the costimulatory factors on the membrane of APCs act as the second signal. Generally, DCs capture and process exogenous antigen peptides into antigen peptide/MHC II molecules in order to activate $\mathrm{CD} 4^{+}$ helper $\mathrm{T}$ cells, and endogenous antigen into antigen peptide/ MHC I molecules for $\mathrm{CD}^{+} \mathrm{T}$ cells $(27,28)$.

In tumors, different subtypes of DCs play divergent roles. Conventional dendritic cell type 1 ( $\mathrm{cDC} 1$ ) and conventional dendritic cell type 2 (cDC2) are two subtypes of cDCs. $\mathrm{CDC1}$ is the main DC subtype that activates $\mathrm{CD}^{+} \mathrm{T}$ cells through the antigen cross-presentation process (29), while cDC2 secretes IL10 , IL-12, IL-23, and TNF- $\beta$ to stimulate the differentiation of the $\mathrm{CD}^{+} \mathrm{T}$ cells (30). It is $\mathrm{cDCs}$ that mainly present tumor antigens and promote antitumor effects.

Plasmacytoid DCs (pDCs) may be involved in both tumor protective processes and tumor-suppressive processes. On one side, pDCs mainly secret type I IFN, which is essential antitumor cytokine (31). On the other side, pDCs induce immunosuppressive cells, leading to a poor outcome $(25,32)$. Due to potentially bidirectional effect, the role of pDCs may be dependent on the tumor microenvironment. pDC is the main subtype of DCs in the tumor sites of ovarian cancer (33), and the infiltration of pDCs in the ovarian cancer microenvironment has a negative association 


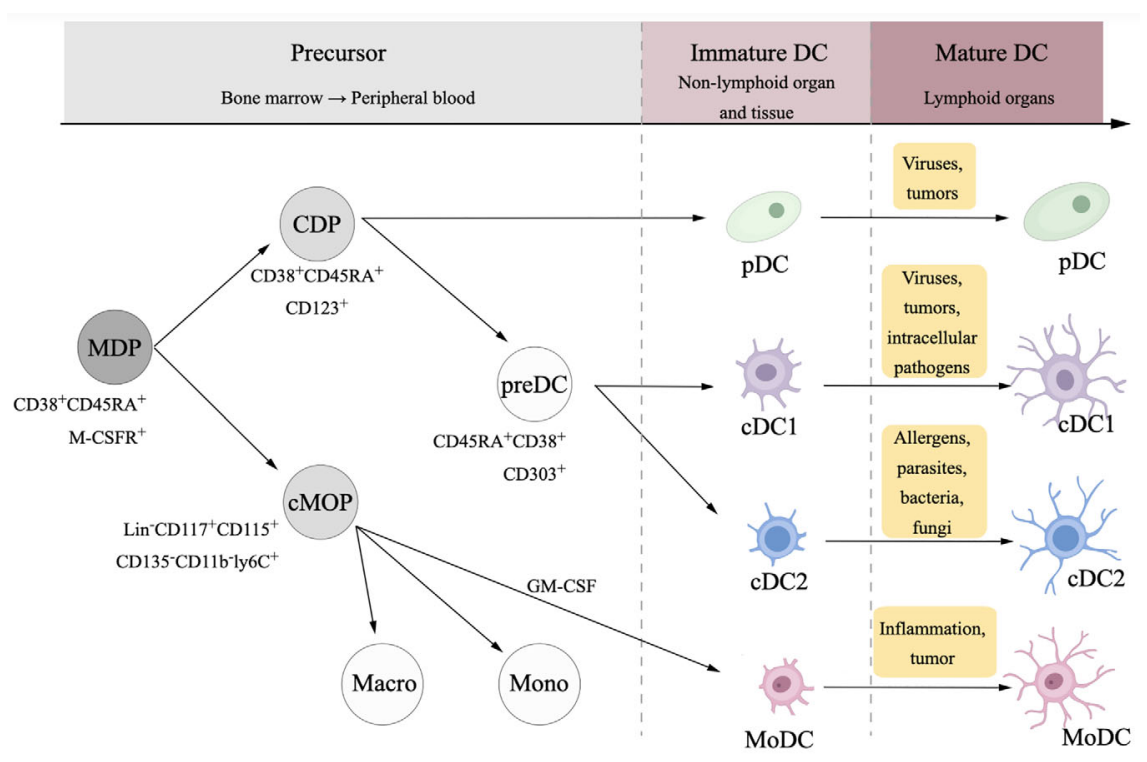

FIGURE 1 | Differentiation and maturation of dendritic cell (DC). DCs and monocytes originate from a common ancestor, namely macrophage dendritic cell progenitor (MDP). MDPs differentiate to common monocyte progenitors (cMOPs) and common DC progenitors (CDPs). cMOPs generally differentiate into monocytes and macrophages, while in some situations with pro-inflammatory context, cMOPs could be stimulated by granulocyte-macrophage colony stimulating factor (GMCSF) then differentiate to monocyte-derived dendritic cells (MoDCs). CDPs differentiate to two subsets, plasmacytoid DCs (pDCs), and myeloid dendritic DCs, which is usually called conventional DCs (cDCs).

with the prognosis (34), but the pDC in response to TLR could release IFN- $\alpha$, although such type of function is weaker than that in the peripheral blood (35). The involvement of DCs in antitumor effects may be disturbed in ovarian cancer, which indicates a potential benefit of DC vaccines.

Monocyte-derived dendritic cells (MoDCs) originate from monocytes in the peripheral blood. The differentiation of MoDCs is commonly induced by GM-CSF and IL-4, followed by the maturation of immature MoDCs stimulated by tumorassociated antigens and other agents (36). MoDCs mainly respond to inflammation in the mouse, but human MoDCs are mostly studied in vitro, and their function depends on the stimulatory signals in the culture.

\section{DENDRITIC CELL DYSFUNCTION IN THE TUMOR MICROENVIRONMENT}

Ovarian cancer lesions have a high degree of DC infiltration, but infiltrated DCs have low efficacy of antigen presentation due to DC tolerance, which is marked by downregulated expression of costimulatory molecules on the surface of DC cells (37), as well as having weaker antigen-presenting ability. DCs also act to assist tumor cells in some situations. In the tumor microenvironment, it has been confirmed that many aspects could induce dysfunction of DCs, as discussed below.

Immune checkpoint signaling may participate in DC dysfunction. The combination of programmed cell death protein 1 (PD-1) on $\mathrm{T}$ cells and programmed death-1 ligand
(PD-L1) on tumor cells leads to the programmed death of the T cells. Ovarian cancer cells could upregulate PD-L1 in DCs by secreting TGF- $\beta$ and $\mathrm{PGE}_{2}$ into the microenvironment (38), enhancing their inhibition of the $\mathrm{T}$ cell immune response. PD-1 inhibitors could restore the capacity of DC, thus enhancing their antitumor effect in ovarian cancer (39). Specific DCs interact with immunosuppressive cells to disturb the antitumor effect. Inducible costimulatory molecule (ICOS) is expressed on the immunosuppressive Treg cells, and pDCs in the ovarian cancer microenvironment activate Treg by expressing ICOS ligand, leading to tumor progression (40).

Some metabolic factors could induce DC dysfunction, including dysfunction of amino acid metabolism and lipid metabolism. The overexpression of indoleamine 2,3-dioxygenase (IDO) in DCs plays an immunosuppressive role. IDO is an essential enzyme in amino acid metabolism, which turns tryptophan into kynurenine. TGF- $\beta$ released by tumor cells can upregulate the expression of IDO in pDC and the secretion of cytokine CCL22, which recruits Tregs into the tumor microenvironment. IDO-expressing DCs reduce the concentration of tryptophan near Tregs and keep Tregs in an immunosuppressive state via tryptophan-induced mTORC-Akt signaling (41). Clinical trials have reported that IDO inhibitors lead to a decreased level of the products of IDO in solid tumors (42), which could be used as a combined agent in DC immunotherapy. Additionally, in response to the endoplasmic reticulum stress induced by the byproducts of lipid peroxidation, the transcription factor XBP1 is activated and this leads to lipid body accumulation in tumor-infiltrating DCs, pushing DCs into a tolerant state in the ovarian cancer microenvironment (43). 
Insulin-like growth factor (IGF) also has impacts on the DCs in ovarian cancer. The IGF participate in cell proliferation as well as in protein synthesis and growth through the RAS-ERK and PI3K-AKT pathways (44). DCs treated with IGF fail to mature and secret higher levels of IL-10 as well as TNF- $\alpha$, which are suppressive immune factors in the ovarian cancer microenvironment (45). The insulin-like growth factor type I receptor (IGF1R) is highly expressed in ovarian cancer and is negatively related to the differentiation of DCs towards cDCs (46). IGF1R inhibitors rebuild the DC-mediated antitumor effect (45), which suggests that the IGF axis may induce DCs to enter a dysfunctional state.

In conclusion, immunosuppressive signals in these aspects lead to a dysfunctional state of the DCs in the ovarian cancer microenvironment. Theoretically, infusion of functional DCs into the body could avoid infiltrating in the tumor microenvironment and instead make direct contact with the $\mathrm{T}$ cells in the lymph nodes, which compensates for DC dysfunction state. Based on this, DC vaccines could restore the tumor antigen-presenting ability to elicit antitumor effects.

\section{ELEMENTS OF MANUFACTURING DENDRITIC CELL VACCINES FOR OVARIAN CANCER}

The common routine of DC vaccine manufacturing includes several elements: (1) obtaining human DC developmental potential cells through apheresis; (2) stimulating autologous immature DCs into a mature state in vitro, in which process the DCs are usually activated by a cocktail of various cytokines, Toll-like receptors agonists and other activators; and (3) loading the immature DCs with tumor-associated antigens, namely, DCs being cocultured with antigens in the form of peptides, proteins, tumor cell lysates or tumor cells. After these steps, the mature DCs are gathered and vaccinated back to the patients.

Preclinical and clinical studies are exploring various alternatives of each element in the manufacture of DC vaccines to achieve a better efficacy in the treatment of ovarian cancer. These elements are discussed separately below.

\section{Selecting Appropriate Dendritic Cell Subtypes for Vaccination}

The subtypes of autologous DC chosen for vaccine manufacture show various antigen presenting potential, which might affect the efficacy of DC vaccines. In preclinical and clinical studies of the DC vaccines in tumors, DC subtypes selected from peripheral blood cells through apheresis include MoDCs, cDCs and Langerhans cell-type DCs $(13,30)$. The DC subtypes targeted to improve antitumor immune responses in clinical studies of the vaccines targeting DC in vivo and ex vivo are distinct and might be dependent on the cancer types (31). The vaccines targeting DCs in vivo do not need apheresis to gather autologous DCs for vaccine manufacturing, and instead, specific antigens targeting receptors on DCs in vivo are injected into the body, such as the vaccine CDX-1401 targeting DEC205 ${ }^{+} \mathrm{cDC} 1 \mathrm{~s}$ in multiple tumors including ovarian cancer, which contains the DEC205 antibody fused with NY-ESO-1 and a TLR agonist (47).

The vaccines targeting DCs ex vivo are based on peripheral blood cells gathered from apheresis. Among all subtypes, MoDCs are most frequently used for targeting DCs ex vivo, mainly because the count of DCs in peripheral blood cells is not sufficient to produce a vaccine, but the count of monocytes is higher, and the monocytes cultured in vitro provide relatively abundant DCs relative to other origins. However, MoDCs show an unsatisfying effect in eliciting CTL responses compared to Langerhans cells in the treatment of melanoma $(13,48)$. cDCs used for vaccines are also confirmed to superior to MoDCs in eliciting systemic and long-lasting immune responses. Additionally, cDCs could enhance the efficacy of immune check point blockers (49). Flow cytometry and immune bead sorting have made it possible to select specific DC subtypes to induce specific CTL activation. However, there still a lack of evidence to confirm which subtype of DCs is the best choice.

$\mathrm{cDC} 1, \mathrm{cDC} 2$, and $\mathrm{pDC}$ are found in ovarian cancer, with a lower rate of both $\mathrm{CDC}$ and $\mathrm{pDC}$ in the peripheral blood compared with healthy control $(33,35)$. The ratio of $\mathrm{cDC}$ and pDC varies between peripheral blood, ascites and tumor sites. According to The most prominent subsets of $\mathrm{DCs}$ is $\mathrm{pDC}$ in ascites (50) and tumor sites (34), while cDC is more than pDC in the peripheral blood (35), which suggests that peripheral blood could be a proper resource of the DCs for manufacturing.

However, the counts of $\mathrm{cDCs}$ is hardly sufficient for vaccine manufacturing, in most clinical studies on DC vaccines in ovarian cancer, DCs used for vaccine manufacture are MoDCs. Mononuclear cells are isolated from peripheral blood through apheresis and are cultured in vitro with GM-CSF and IL-4 for several days. To monitor the cell components of the DC vaccine, the expression of the markers on DCs are analyzed, mainly including $\mathrm{CD} 11 \mathrm{c}^{+}, \mathrm{HLA}-\mathrm{DR}^{+}, \mathrm{HLA}-\mathrm{ABC}^{+}, \mathrm{CD} 40^{+}, \mathrm{CD}^{+}$, $\mathrm{CD}^{2} 3^{+}, \mathrm{CD}^{+} 6^{+}$, and $\mathrm{CCR}^{+}(17,51)$. Notably, these markers are not sufficient to distinguish MoDCs from other subtypes of DCs, and the final DC vaccine is a mixture of DC and a small fraction of other peripheral blood cells.

To conclude, MoDCs have been most frequently used for manufacturing DC vaccines in the current clinical study on ovarian cancer, and it is unclear if other subtypes of DCs would be more beneficial.

\section{Loading Tumor-Associated Antigens}

To induce DCs to recognize and present specific tumor antigens, several potential methods are tested, including pulsing DCs with tumor-associated antigens, inducing tumor cells and DCs into fusion cells, and mRNA transferring. The tumor-associated antigens are most frequently used in the clinical trials, while the other two are limited to case reports or clinical studies of a small population. The antigens to load DCs determine the specificity of the antitumor effect, production costs, and side effects of the DC vaccine, which makes it an essential step. Among current DC vaccine research on various cancers, immature DCs are loaded with various forms of tumorassociated antigens, including peptides, proteins, and whole 
tumor lysates. Published studies of different types of DC vaccines in ovarian cancer are listed in Table $\mathbf{1}$.

For targeting antigens expressed on the ovarian cancer cells, DCs are loaded with one or more peptides/proteins. Proto-oncogene HER-2/neu-derived peptides are used to load DC, such as E75 (epitope recognized by cytotoxic T lymphocytes, amino acids 369377) (52, 63), GP2 (transmembrane part, amino acids 654-662) (52, 64), and recombinant fusion antigen BA7072, which contains both intracellular and extracellular domain of HER-2/neu (65). Wilms tumor 1 (WT-1) is an intracellular protein that overexpressed in many solid tumors including ovarian cancer, therefore it is targeted by specific cytotoxic T lymphocytes when presented by $\mathrm{MHC}$ molecules (66). DC incubated with a MHC class I-restricted modified WT-1 derived peptide [HLA-A ${ }^{\star} 2402$-restricted, amino acids 235-243 (51), or HLA-A*0201/0206-restricted (55)] successfully induce WT-1 specific CTL effect, with the assist of a streptococcal primer OK-432 (51). Epithelial mucin 1 (MUC1) is a membrane glycoprotein, which is expressed in $90 \%$ of ovarian cancer samples $(52,67,68)$. Other peptides for pulsing DCs are selected based on the expression rate in the ovarian cancer, including human telomerase reverse transcriptase (hTERT) (53), pan-DR epitope peptides (PADRE) (53), and p53 peptide (16). Most of the DC vaccines loaded with peptides/proteins have induced peptide/protein-specific IFN- $\gamma$ secreting $\mathrm{T}$ cells proliferation after doses of the vaccines. The overall clinical response rate was approximately $26 \%(16,51-53,55,65)$ and the disease stabilization period ranged from several weeks to months, but the clinical responses were limited to stable disease, followed by progressive disease.

To load DCs with antigens that contain a wider epitope rather than single epitope of derivative peptides, fusion peptides have also been tested. For example, MUC1 fusion peptides was conjugated to mannan for synthesizing mannosylated mucin 1 fusion peptide (M-FP) $(54,69)$. In a phase 2 single-arm study, 21 patients received at least three doses of vaccine DCs loaded with M-FP. Monitored by serum CA-125, two patients had a major response during the study, and the response duration was 57 and 71 weeks, respectively. However, the response rate was only $19 \%$, and the IFN- $\gamma$ releasing immune response was weak to moderate (54).

To further improve the immune and clinical response rate, tumor cell lysates were considered to be more effective cancerspecific antigens. These whole ovarian cancer cell antigens could be obtained from SKOV3 ovarian cancer cell lines (58), fresh tumor biopsy samples $(17,59)$, or paraffin block allogenic tumor sample (60). For enhanced immunogenicity of tumor antigens, tumor cells were induced to necrosis by repeating freeze-thaw cycles, or induced to apoptosis by irradiation, as well as oxidized by hypochlorous acid $(\mathrm{HOCl})$. Preclinical study has compared the efficacy of DCs pulsed with different tumor lysates. DC vaccines pulsed with tumor lysates that were prepared through $\mathrm{HOCl}$ oxidization followed by freeze-thaw cycles induced higher levels of IFN- $\gamma$ secreting $T$ cells compared with that prepared through irradiation followed by freeze-thaw cycles, or simply freeze-thaw cycles (58). In clinical trials, the frequency of IFN- $\gamma$ secreting $\mathrm{T}$ cells increased significantly after DC treatment in most of these studies, and the increase of tumor-reactive $\mathrm{T}$ cells was associated with clinical benefits $(17,59)$.

As well as peptide-, protein-, and whole tumor lysate-loaded DCs, the use of mRNA transfected DCs have also been reported as a case report $(56,70)$. Additionally, tumor-DC fusion cell vaccines in ovarian cancer treatment have been tested $(71,72)$, but lack sufficient clinical trial data.

TABLE 1 | The antigen of dendritic cell (DC) vaccines used in the clinicial trials in ovarian cancer.

\begin{tabular}{|c|c|c|}
\hline Antigen loaded & Clinical effect (Survival period) & Published Year \\
\hline \multirow[t]{4}{*}{ Her-2/neu or MUC1 peptide } & - & $2000(52)$ \\
\hline & In arms 1,2: & $2012(53)$ \\
\hline & $\begin{array}{l}\text { estimated } 3 \text {-year PFS: } 40 \% \text { vs } 80 \% \text {; } \\
\text { estimated 3-year OS: } 80 \% \text { vs 100\% }\end{array}$ & \\
\hline & - & $2014(54)$ \\
\hline \multirow[t]{2}{*}{ p53 peptide } & For arms 1/2: & $2012(16)$ \\
\hline & $\begin{array}{l}\text { median PFS: } 4.2 \text { months vs } 8.7 \text { months; } \\
\text { median OS: } 40.8 \text { months vs } 29.6 \text { months }\end{array}$ & \\
\hline \multirow[t]{4}{*}{ MHC class I-restricted Wilms tumor 1 (WT1) peptide } & Median OS: 14.5 months & $2014(55)$ \\
\hline & Median OS: 13.1 months & $2019(51)$ \\
\hline & PFS: 0,2 months & $2013(56)$ \\
\hline & OS: 70,64 months & \\
\hline Neoantigen peptides & OS since the $1^{\text {st }}$ dose: 15 months & $2020(57)$ \\
\hline Hypochlorous acid (HOCl)-oxidized autologous tumor lysate & PFS: 1 patient 36 months, 1 patient 44 months & $2013(58)$ \\
\hline \multirow[t]{5}{*}{ Autologous tumor cell lysate } & - & $2013(59)$ \\
\hline & Median PFS: 176 days & $2014(60)$ \\
\hline & median OS: 198 days & \\
\hline & In cohort 2, median OS: 11 months; & $2018(17)$ \\
\hline & In cohort 3: median OS > 25 months; & \\
\hline \multirow[t]{4}{*}{ Keyhole limpet haemocyanin (KLH) and autologous tumor cell lysate } & - & $2002(61)$ \\
\hline & Median PFS: 19.2 months; & $2015(62)$ \\
\hline & median OS: 43.8 months & \\
\hline & OS: $64.95 \pm 7.62$ months & \\
\hline
\end{tabular}

PFS, progression free survival; OS, overall survival. 
In addition to ovarian cancer-associated antigens, nonspecific antigens are also involved in DC vaccine trials. Keyhole limpet hemocyanin $(\mathrm{KLH})$ is a foreign helper protein, which could enhance antitumor immunity by stimulating the IFN- $\gamma$ production of T cells (73). DC vaccines have been pulsed with KLH and tumor lysate simultaneously; however, some patients developed KLH-specific T cell proliferation but failed to develop tumor antigen-specific $\mathrm{T}$ cell proliferation (61). KLH has also been added as a surrogate indicator of a DC vaccine (62), but controlled studies are needed to confirm the association between $\mathrm{KLH}$-specific immune responses and the efficacy of DC vaccines.

\section{Personalized Dendritic Cell Vaccines Based on Next-Generation Sequencing}

Traditionally, DC vaccines are loaded with the tumor-associated antigens mentioned above, but their antitumor effect might be relatively narrow. For the pursuit of a broader antitumor effect, emerging personalized DC vaccines are being developed to target patient-specific neoantigens, namely, tumor-specific antigens that are derived from individual nonsynonymous single nucleotide variations. To validate the individual neoantigens, whole exome sequencing and bioinformatic analysis (e.g., fetchGWI, NETMHC) are combined, complemented or not by high throughput qPCR essays and mass spectrometry (74). To manufacture personalized DC vaccines, DCs are loaded with these candidate individual neoantigens through neoantigen gene-encoding peptides stimulation (75) or mRNA transfection $(76,77)$.

As a recent cohort study reported, autologous DCs loaded with autologous tumor cell lysate also successfully elicited a personalized neoepitope-specific $\mathrm{T}$ cell reaction as predicted (17). In this study, whole-exome sequencing and bioinformatic algorithms were used to predict individual neoantigens, and $\mathrm{T}$ cell clones targeted to these neoantigens are amplified after DC treatment. However, the paucity of the tumor sample attained from surgery might be an obstacle, and it is unclear whether the whole tumor lysate would induce DCs to a dysfunctional state as tumor cells do in the microenvironment. A protocol has been published to compare personalized DC vaccines pulsed either with private peptides or with whole tumor lysates (78), which hopefully will provide further evidence about the production of personalized DC vaccines in ovarian cancer.

\section{CLINICAL STUDIES ON DENDRITIC CELL VACCINES IN OVARIAN CANCER}

The safety and efficacy of DC vaccines in the treatment of ovarian cancer has been reported by over 20 studies, including case reports, pilot studies and clinical trials (Table 2). These studies either contain multitumors including ovarian cancer (shown with a star mark in Table 2), or simply focus on ovarian cancer. Currently, there are 20 registered clinical trials on ClinicalTrials.gov (searched by "ovarian cancer" and "dendritic cell vaccine"). Eleven clinical trials have been completed, three clinical trials are active or recruiting, and two clinical trials are not yet recruiting (Table 3). It is important to point out most of the current clinical trials have stagnated before phase II. Recently, a phase-III multicenter, randomized, doubleblind, placebo-controlled trial has been registered but is not yet recruiting (NCT03905902), which might provide evidence for the usage of DC vaccines in relapsed platinum-sensitive ovarian cancer patients in the future.

\section{Safety of Dendritic Cell Vaccines}

The safety of DC vaccines has drawn great attention for the reason that it might alter the level of immune cells, cytokines, and chemokines in vivo. Fortunately, most of the DC vaccines have been well-tolerated by ovarian cancer patients involved in clinical studies. According to the Common Terminology Criteria for Adverse Events, each symptom of side effects is graded by the degree of severity. As listed in Table 1, most of the reported side effects are grade 1 or 2 , and common ones are local skin reactions, fatigue, pain, flu-like symptoms, myalgia, fever, nausea, and vomiting $(17,51,53-55,59-62,79)$.

There are several studies reporting serious toxicity of DC vaccines, especially those studies using a combination therapy. In a two-arm, phase II trial of the p53 peptide cancer vaccine and DC vaccine (16), all 21 patients reported a local skin reaction. In the arm that received a combination of DC vaccine loaded with p53 peptide, lymphopenia and fatigue were reported by at least 3 patients. Other reported grade III/IV vaccine-related toxicities are elevated levels of ALT and AST, fever, hypocalcemia, memory loss and rigors. Notably, according to the subgroup analysis in this study, significant toxicity was ascribed to the IL-2 administration. In a phase I trial of DC vaccine in the maintenance therapy for ovarian cancer (17), Tanyi et al. reported that more adverse events emerged in the patients who received a combination of DC vaccine, bevacizumab, and cyclophosphamide. There were grade 3 or 4 toxicities reported by 1 patient each: vasovagal disorder, arthralgia, hip replacement, small intestinal obstruction, anemia, cardiac arrhythmia, and decreased lymphocyte count, and 2 patients reported hypertension. Because these adverse symptoms are also common among ovarian cancer patients following chemotherapy, more evidence is needed to confirm whether these grade 3 or 4 toxicities are related to DC vaccines.

To conclude, DC vaccines are well tolerated in most cases, but a combination therapy of DC vaccines and chemotherapy or immunotherapy should be undertaken only with caution.

\section{The Efficacy of Dendritic Cell Vaccines in Maintenance Therapy}

During the past 20 years, DC vaccines for the treatment of ovarian cancer have been most frequently tested during the maintenance therapy $(16,17,51,53,55,58,59,65)$, with or without other drugs (Figure 2). Recurrent ovarian cancer patients are involved in these clinical trials, including chemotherapy-sensitive and chemotherapy-resistant recurrences. Cheryl Lai-Lai Chiang and Lana E. Kandalaft et al. reported a pilot study on a DC vaccine pulsed with $\mathrm{HOCl}$ oxidized tumor lysate in five ovarian cancer patients with recurrence (58). After receiving five doses of DC vaccines 
TABLE 2 | The clinical trials of DC vaccines in ovarian cancer.

\begin{tabular}{|c|c|c|c|c|c|}
\hline $\begin{array}{l}\text { Published } \\
\text { Year }\end{array}$ & Multiple arms of the trial & NO. & $\begin{array}{l}\text { Phase of } \\
\text { study }\end{array}$ & \multicolumn{2}{|c|}{ Clinical effect } \\
\hline $2000(52)$ & Single arm & $3^{\star}$ & $1 / 11$ & 2 SD and 1 PD after 3 doses & - \\
\hline $2012(16)$ & $\begin{array}{l}\text { Arm1 ( } n=14) \text { : wild type p53 peptide; } \\
\text { Arm2 }(n=7) \text { : DC vaccines loaded with p53 peptide }\end{array}$ & 21 & ॥ & $\begin{array}{l}\text { Arm1: } 2 \text { NED, } 9 \text { RD; } \\
\text { Arm2: } 2 \text { NED, } 5 \text { RD }\end{array}$ & $\begin{array}{l}\text { For arms 1/2: } \\
\text { median PFS: } 4.2 \text { months vs } 8.7 \\
\text { months; } \\
\text { median OS: } 40.8 \text { months vs } 29.6 \\
\text { months }\end{array}$ \\
\hline $2014(55)$ & - & 56 & $\begin{array}{l}\text { retrospective } \\
\text { study }\end{array}$ & $1 \mathrm{PR}, 7 \mathrm{SD}, 42 \mathrm{PD}, 7 \mathrm{NE}$ & Median OS: 14.5 months \\
\hline $2014(54)$ & - & 28 & $\|$ & $1 \mathrm{CR}, 1 \mathrm{PR}, 2 \mathrm{SD}, 24 \mathrm{PD}$ & - \\
\hline $2019(51)$ & - & $3^{*}$ & I/II & $2 \mathrm{SD}, 1 \mathrm{PD}$ & Median OS: 13.1 months \\
\hline $2014(60)$ & - & $7^{*}$ & $\|$ & $1 \mathrm{PR}, 2 \mathrm{SD}, 4 \mathrm{PD}$ & $\begin{array}{l}\text { Median PFS: } 176 \text { days } \\
\text { median OS: } 198 \text { days }\end{array}$ \\
\hline $2018(17)$ & $\begin{array}{l}\text { Cohort } 1(n=5) \text { : DC vaccine; } \\
\text { Cohort } 2(n=10) \text { : DC vaccine + Bev; } \\
\text { Cohort } 3(n=10) \text { : DC vaccine + Bev + } \\
\text { cyclophosphamide }\end{array}$ & 25 & । & $\begin{array}{l}\text { Cohort 1: } \\
\text { 3 SD, 2 PD; } \\
\text { Cohort 2: } \\
\text { 1 PR, 4 SD, } 5 \text { PD; } \\
\text { Cohort 3: } \\
\text { 1 PR, } 5 \text { SD, } 4 \text { PD }\end{array}$ & $\begin{array}{l}\text { In cohort 2, median OS: } 11 \text { months; } \\
\text { In cohort 3: median OS > } 25 \\
\text { months; }\end{array}$ \\
\hline
\end{tabular}

OC, ovarian cancer; $S D$, stable disease; $P D$, progressive disease; $R D$, recurrent disease; doses, doses of DC vaccinations; NED, no evidence of disease; PFS, progression free survival; OS, overall survival; TILs, tumor infiltrating lymphocytes; Bev, bevacizumab; Treg, regulatory T cells.

${ }^{*}$ Only the data of ovarian cancer patients are shown here, these clinical studies include more than one type of cancer disease.

injected into the inguinal lymph nodes, two chemotherapysensitive recurrent subjects reached stable disease, with progression-free intervals of 36 months and 44 months, respectively. Notably, the PFS responses to DC vaccines of these two patients are longer than the PFS after their previous chemotherapy, which indicates an encouraging effect of elongating remission intervals and a need for further clinical trials with a larger population. Wen Zhang et al. reported a phase I/II study on DC vaccines pulsed with WT1 peptide in three ovarian cancer patients (51). All of these patients were resistant to conventional surgery or chemotherapy, and three chemotherapy-resistant recurrent ovarian cancer patients were involved in this study. Only one patient who had received 10 cycles of chemotherapy responded to the DC vaccines, reaching a state of stable disease and had an improved quality of life. Notwithstanding, it is not fair to conclude that DC vaccines have no effect in chemotherapy-resistant recurrent patients. Compared with the responsive patient in this study, the other two ovarian cancer patients with progressive disease in this study received more cycles of chemotherapy before the trial, namely, they received DC vaccines at a relatively late time. Although the samples involved in these two studies remain limited, it might be more beneficial for ovarian cancer patients to receive DC vaccines at a relatively early time. Due to different study designs, the other clinical studies did not report detailed data or a separate analysis of chemotherapy-sensitive recurrent populations and chemotherapy-resistant recurrent populations, but some of them completed follow-up and survival analysis (Table 1).

To evaluate the efficacy of DC vaccines that are received at a relatively early time, namely, before recurrence, Masanori Kobayashi et al. reported a retrospective study on 56 primary 
TABLE 3 | Clinical trials of dendritic cell (DC) vaccine in ovarian cancer registered on ClinicalTrials.gov.

\begin{tabular}{|c|c|c|c|}
\hline Status (up to 2020.2) & NCT number & Treatment & Number enrolled \\
\hline & NCT03905902 & DCV & 678 \\
\hline \multirow[t]{3}{*}{ Active/Recruiting } & NCT00799110 & DCV+GM-CSF, DCV+ GM-CSF+ Imiquimod & 23 \\
\hline & NCT02111941 & DCV & 19 \\
\hline & NCT00703105 & DCV & 36 \\
\hline \multirow[t]{7}{*}{ Completed } & NCT01617629 & DCV & 9 \\
\hline & NCT00683241 & DCV & 36 \\
\hline & NCT01132014 & DCV & 67 \\
\hline & NCT01522820 & $\mathrm{DCV}+$ Sirolimus & 18 \\
\hline & NCT00844506 & DCV+ Cyclophosphamide & 19 \\
\hline & NCT00648102 & DCV & 36 \\
\hline & NCT00019084 & DCV, DCV+ autologous lymphocytes & 70 \\
\hline
\end{tabular}

DCV, dendritic cell vaccine; GM-CSF, granulocyte-macrophage colony stimulating factor; NK cell, natural killer cell.

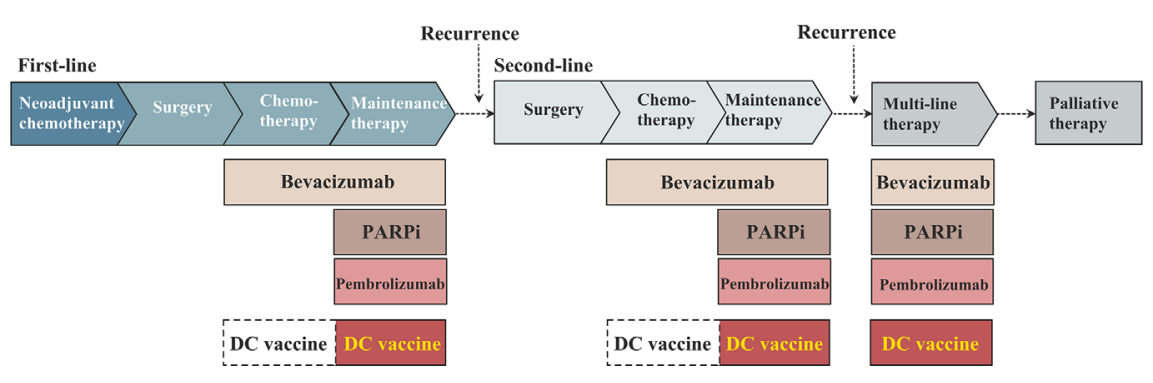

FIGURE 2 | The schema of dendritic cell (DC)-based vaccine in the maintenance treatment in ovarian cancer.

ovarian cancer patients who received DC treatment as maintenance therapy following the initial chemotherapy, and $48 \%$ of the patients involved in this study continuously received platinum-based chemotherapy during DC vaccination (55). All of the patients were injected with 5-7 doses of DC vaccines, and the median survival times from diagnosis and the first dose were 30.4 months and 14.5 months, respectively. These data show that the first PFS after initial treatment was elongated by DC vaccines. An increased level of tumor-antigen specific $\mathrm{T}$ cells were also detected in some subjects, but subjects with immune responses did not obtain a significantly better survival than those without immune responses. However, as a retrospective study with a relatively small sample size, the evidence it provided is not sufficiently strong. Despite this, it provides evidence for the use of DC vaccines as the initial maintenance therapy and confirms that the patient's nutritional state could affect the DC treatment efficacy, which is useful for the design of future studies.

\section{Combination Therapy With Dendritic Cell Vaccines}

In addition to serving as a mono-drug therapy, DC vaccines are also tested in combination with other therapies, including chemotherapies, targeted therapies, immunotherapies, and nonspecific immune-enhancing agents.

Potential synergistic effects of different chemotherapy drugs in ovarian cancer combined with DC vaccines are distinct (80). Paclitaxel is one of the frequently used drugs in chemotherapy for ovarian cancer. Paclitaxel enhances the maturation of early DCs in mice, and DC precursors exposed to a low dose of paclitaxel express higher levels of CD40, MHC-II molecule, and CD86 in response to antigens (81), suggesting a stronger antigen-presenting function. However, most of the patients involved in DC vaccine trials have already completed primary chemotherapy, and only limited evidence is available to help analyzing the effect of DC treatment and chemotherapy at the same time.

Cyclophosphamide is a nonspecific cell phase agent that prevents cell division by suppressing DNA synthesis, although monotherapy with cyclophosphamide acts poorly against ovarian cancer, and combination therapy with it may strengthen the antitumor effect. The synergistic effects of cyclophosphamide are divergent in two clinical studies. In one study, the administration of cyclophosphamide before DC vaccines did not provide additional survival benefits compared with just DC vaccines (53). However, another study suggested cyclophosphamide might strengthen the 
effect of DC vaccines. The 2-year overall survival rates of patients with or without cyclophosphamide prior to receiving DC vaccines are $80 \%$ and $30 \%$, respectively, and the immune response rate to DC treatment was higher in the cyclophosphamide cohort (17). These two studies differ in many aspects, and one of them is that the latter study also used bevacizumab as a combination drug. Bevacizumab targets vascular endothelial growth factor (VEGF) to suppress tumor angiogenesis while cyclophosphamide decreases Treg as well as MDSC (82), indicating a synergistic antitumor effect with immunotherapy in the tumor microenvironment. Unfortunately, there is no DC vaccines clinical study that provides contrasting groups with or without bevacizumab, which needs further attention.

DC-based therapy might be enhanced by other immunotherapies that have synergistic immune effect, including the immune checkpoint blockers and $\mathrm{T}$ cell transfer. It has been demonstrated that immune checkpoint blockers such as anti-PD-1/ PD-L1 could theoretically enhance the antitumor effect of DC vaccines $(38,39)$. However, the expression of PD-L1 on DCs in ovarian cancer patients is moderate compared with on normal ovarian tissues (83), and currently, there is no clinical trial testing the combination of anti-PD-1/PD-L1 and DC vaccines.

Combination therapy with autologous DC and T cells transfer might be beneficial, based on the mechanism that DCs present antigens to $\mathrm{T}$ cells. Kandalaft et al. reported a clinical study on DC treatment followed by autologous $\mathrm{T}$ cell transfer (59). These $\mathrm{T}$ cells were obtained through apheresis after DC treatment and underwent expansion in vitro. Seven recurrent advanced-stage ovarian cancer patients received DC vaccines, and three of them that reached PD or PR after DC vaccination were finally enrolled into a $\mathrm{T}$ cell infusion group. One of them achieved a partial response $(\mathrm{PR})$ after $\mathrm{DC}$ vaccines treatment and later successfully achieved a complete response (CR) after autologous $\mathrm{T}$ cell transfer. The second patient who reached a PR after DC vaccination had disease progression, while the third patient had stable disease after DC vaccination and $\mathrm{T}$ cell transfer. Moreover, tumor-reactive $\mathrm{T}$ cells were detected before $\mathrm{T}$ cell transfusion in the peripheral blood of the CR patient but not in the disease progression patient, which suggests that reconstitution of tumor-reactive $\mathrm{T}$ cells depends on the immune response to $\mathrm{DC}$ vaccines.

Additionally, as a subgroup of $\mathrm{T}$ cells, NK cell-like $\mathrm{T}$ cells recognize antigens presented by DCs in a CD1c-restricted manner and suppress MDSC in the microenvironment (84), which could help to enhance the efficacy of DC vaccines. A clinical trial of dendritic cell vaccines combined with autologous NK cell-like CTLs for treating ovarian cancer patients (NCT03735589) is carrying out.

Other nonspecific immune-enhancing agents have also been tested as combination agents, including IL-2, IL-12, OK-432, and sirolimus. As Soyoung Baek et al. reported, it was safe to use IL-2 simultaneously with DC vaccines (62). However, another clinical trial reported a combination of DC and IL-2 caused grade 3 or 4 side effects and induced Treg expansion (16). Notably, the administration of IL-2 in these two studies differs in dosage and injection sites, which may account for the divergent results. Recombinant human interleukin-12 (rhIL-
12) was used as a combination agent with DC vaccines in various tumors, but limited data reveal the effect of rhIL-12 in clinical trials (71). OK-432 is a streptococcal immunological adjuvant, which is injected simultaneously with DC vaccines but has no significant association with the survival of the patients $(51,55)$.

\section{The Administration Scheme of Dendritic Cell Vaccines}

There is no consensus on the administration scheme of DC vaccines in the clinical context. DC vaccines tested in ovarian cancer patients are administered intradermally $(54,55,59,61)$, subcutaneously $(52,53,62,71)$, intranodally $(17,58)$ or intravenously $(16,60)$. The injection route of vaccination might affect the migration of DCs to lymph nodes, as well as the contact between DCs and $\mathrm{T}$ cells. Intranodal vaccination came into the spotlight in recent years. It is reported that far more DCs reach the T-cell areas of the lymph nodes in the melanoma patients administered DC vaccines intranodally, notwithstanding, the immune responses were similar between the two groups (85). But the areas of drainage lymph nodes vary a lot in different cancers, limited data is available to confirm the strengths and weaknesses of different injection routes in the ovarian cancer patients, which left a unrevealed answer for further clinical studies.

The vaccination schemes vary greatly between different studies. In some trials, patients receive a fixed number of DC vaccines at fixed intervals, such as two doses at a 4-week interval (62) or four doses at a 3-week interval (53). In other clinical trials, several doses of DC vaccine are administered to prime the immune response, and residual doses are administered at a longer time interval, for example, five doses every 3 weeks and residual doses per month (17). However, there is no consensus on how to arrange vaccination and examination schedules, which should be carefully considered with when designing clinical trials.

In addition to injection routes, limited evidence is available to confirm the best intervals of injection, the total number of doses to receive, and the administration pathway. Further studies are needed to confirm the administration scheme that most effectively promotes the functional process of DCs in vivo.

\section{BIOMARKERS TO MONITOR AND PREDICT THE EFFICACY OF DENDRITIC CELL VACCINES}

Although PFS and OS are considered as the most reliable assessment criteria, survival analysis may take several years to complete. Therefore, sensitive immune markers will be the cornerstone for monitoring and predicting the responses to DC vaccines. Some of the preclinical and clinical studies of DC vaccines have made exploration on two key issues: how to assess the immune responses and how to predict the clinical responses $(58,59,62)$, an alteration of immune cells, especially $\mathrm{T}$ cells, are in the spotlight of the stage. 


\section{Immune Biomarkers to Predict the Effect of Dendritic Cell Vaccines}

Studies on DC vaccines in different types of cancer are exploring biomarkers to predict the clinical response of DC-based treatment. Several types of biomarkers have been reported, including immune cells, cytokines, chemokines, membrane proteins and genes. These immune biomarkers to monitor and predict the effect of DC vaccines in ovarian cancer and other tumors are discussed below.

\section{Immune Biomarkers Based on Peripheral Blood Samples}

$\mathrm{T}$ cell reactivity is the cornerstone of DC vaccine immunoreactivity. In clinical studies of DC vaccines in ovarian cancer patients, alterations of immune cells in the peripheral blood sample after DCs infusion have been demonstrated, including the activation of specific antigen-induced IFN- $\gamma$ secreting $\mathrm{CD}^{+} \mathrm{T}$ cells $(58,59,62)$, an increased count of $\mathrm{CD} 4^{+} \mathrm{T}$ cells (16) and Th1 polarization (58, 86). These could be regarded as basic indicators, but a monitoring scheme of a comprehensive immune cell profile following DC vaccines has not been established. It should based on both the counts and the functions of immune cells.

The cytokines and chemokines secreted by immune cells are tested as functional indicators. There are significantly increased levels of Th1-polarizing chemokines and cytokines such as IL-12, IL-1R $\alpha$, TNF- $\alpha$ after DC vaccine treatment of ovarian cancer patients, while Th2-priming cytokines IL-4, IL-5, and IL13 are at low levels suggesting that DC vaccines elicit a Th- 1 antitumor effect (58). A recent clinical study confirmed that DC vaccineprimed $\mathrm{CD}^{+} \mathrm{T}$ cells to mainly secret TNF- $\alpha$ and IL-2, while $\mathrm{CD} 8^{+} \mathrm{T}$ cells to mainly secret IFN- $\gamma$ and TNF- $\alpha$ (17).

The array of T-cell receptor (TCR) sequences present can be detected by next-generation deep sequencing, namely, the TCR repertoire, which could be used to evaluate the immune response of DC vaccines. According to a cohort study in ovarian cancer patients, there is no overlap of the TCR repertoire between peripheral blood T cells pre- and post- DC vaccines, suggesting that $\mathrm{DC}$ vaccines have primed a novel $\mathrm{T}$ cell immune response. Moreover, novel T cells manifest high avidity due to high-affinity TCR clones, which benefits DC vaccine-induced antitumor effects (17).

To conclude, the immune markers in the peripheral blood that are altered after DC treatment might be proper indicators of the immune response.

\section{Immune Biomarkers in the Ovarian Cancer Microenvironment}

Beyond surface markers and the secreting function of $\mathrm{T}$ cells in the peripheral blood, characteristics of the ovarian cancer microenvironment might be predictors as well. In the clinical context, a tumor sample could only be obtained during biopsy or surgery, and thus the markers on tumor samples could be utilized to detect infiltration of a sensitive population rather than evaluation indicators of the vaccines.

As a clinical study in glioma patients reported, there was a higher overlap of TCR repertoires between T cells from both peripheral blood and tumor sites, and an increased overlap after DC treatment predicts improved immune and clinical responses to $\mathrm{DC}$ vaccines (87).

The molecules on the membrane of $\mathrm{T}$ cells can also be taken into consideration. The count of $\mathrm{PD}-1^{+}$lymphocytes and the percentage of PD- $1^{+} \mathrm{CD} 8^{+} \mathrm{T}$ cells are negative prognostic indicators for overall survival and progression-free survival among glioblastoma patients received autologous DCs but not in the control group, suggesting that $\mathrm{PD}-1^{+} \mathrm{T}$ cells infiltrating might be a biomarker for DC treatment (88). In contrast, lower expression of $\mathrm{B} 7-\mathrm{H} 4$, a member of the $\mathrm{B} 7$ family, is associated with a better response to $\mathrm{DC}$ vaccines in glioblastoma (89). However, neither PD- $1^{+} \mathrm{CD} 8^{+} \mathrm{T}$ cells nor $\mathrm{B} 7$ family molecules has been tested in clinical trials of $\mathrm{DC}$ vaccines in ovarian cancer. Further studies are needed to describe the potential of $\mathrm{T}$ cells in response to $\mathrm{DC}$ vaccination.

One of the limitations in these clinical trials is the lack of the comparison of tumor samples before and after DC treatment, but in the mouse model, such change of ovarian cancer microenvironment has been illustrated, DC vaccination promotes the proliferation of $\mathrm{CD}^{+} \mathrm{T}$ cells and $\mathrm{CD} 8^{+} \mathrm{T}$ cells and decreases the level of MDSCs, Tregs and tumor-associated macrophages (90).

The localization of immune cells infiltrating in tumor sites may has potential impact. Ovarian cancer used to be regarded as "immune desert" due to low level of infiltrating immune cells, but studies have reported the existence of tertiary lymphoid structures (TLSs) in tumor sites, which harbor B cells, T cells and DC-LAMP $^{+}$dendritic cells (91). The infiltration of DC-LAMP ${ }^{+}$ dendritic cells is associated with better prognosis in ovarian cancer patients (92), but whether DC infusion promotes the build of TLS remains to be explored in the future.

Based on the markers discussed above, an ideal immune response-predicting biomarker should satisfy several points: a strong association with the treatment response or prognosis, a quick examination method to monitor, and a relatively high sensitivity and specificity. However, due to a relatively low response rate to DC vaccines in ovarian cancer compared with other cancers, some biomarkers tested in ovarian cancer but limited progress has been achieved. To explore biomarkers for DC-based treatment responses in ovarian cancer, the basic immune status of the patient, immune characteristics of ovarian cancer and potential drug targets should be taken into consideration. Additional welldesigned clinical trials are needed to promote this field forward.

\section{Association Between Immune Responses and Clinical Responses in Ovarian Cancer}

An increasing number of studies have focused on the association between immunoreactivity and the clinical responsiveness of tumor immunotherapy. If specific immune markers can be determined to predict an individual's immune reactivity to the vaccine, and the long-term clinical benefit of DC vaccines can be assessed by monitoring changes in immune marker levels, it would help to adjust the vaccine dosage and determine treatment endpoints.

The immunoreactivity of DC vaccines in ovarian cancer is mainly described by the alteration of the following immune cells: $\mathrm{CD} 8^{+} \mathrm{T}$ cells, $\mathrm{CD} 4^{+} \mathrm{T}$ cells, Tregs and NK cells. As a pilot study with 5 recurrent ovarian cancer patients reported, in the patients 
with a $\mathrm{T}$ cell immune response to $\mathrm{DC}$ vaccines, the second PFS following DC treatment was longer than the first PFS before the DC vaccine (58). In some studies that have monitored both immune and clinical responses, $\mathrm{T}$ cell reactivity is related to clinical benefit, such as a partial tumor response (PR), disease stabilization, and prolonged survival without progression (59, 62), however, these associations between DC-activated $\mathrm{T}$ cells and clinical outcome were not stable. A decrease in Tregs after DC treatment could be an immune response indicator, but not a single biomarker to predict clinical response, because a reduction in Tregs has been detected in both stable disease and progressive disease patients $(58,59)$. Increased NK cell activity after DC treatment was found in ovarian cancer patients in a pilot study. More than half of the enrolled patients presented with increased NK cell activity, but this change was not significantly correlated with clinical prognosis (62). Other immune cells are potential predictors, such as myeloid-derived suppressor cells (MDSCs), which have an immuno-suppressive effect on immunotherapy. Immune responses to DC vaccines are significantly associated with fewer MDSCs (51), which calls for further follow-up to confirm its association with clinical outcomes.

Additionally, serum antibodies IgG and IgM reflect a basic state of the immune environment, which could also bridge the immune and clinical responses of DC vaccines. Patients show weak antibody responses based on IgG and IgM induced by ovarian cancer-specific antigens prior to DC treatment, suggesting a suppressive immune environment in ovarian cancer (54). After DC treatment, the serum IgG and IgM are higher than the baseline in some ovarian cancer patients, indicating a priming immune response in vivo (59). However, how long this alteration is maintained and whether it could benefit survival remain to be illustrated.

Currently, studies on DC vaccines differ from each other in aspects of the scale of sampling, vaccine production, and vaccination schemes, which underscores the difficulty in drawing consistent conclusions. Future large-scale cohort studies with a complete follow-up will add additional power to reveal the link between immune responses and clinical responses.

\section{Timepoints to Monitor Immune Markers}

Immunotherapy such as DC vaccines may cause short-term and long-term effects. Immune responses may occur within hours to days or potentially lead to long-term changes in the components of the immune microenvironment. It is essential to capture the alterations of immune reactivity at the correct time, especially in clinical trials where it is unethical to conduct invasive examinations too frequently. In clinical trials of DC vaccines for the treatment of ovarian cancer, there was a significant difference in $\mathrm{T}$-cell reactivity before and after receiving $\mathrm{DC}$ (17). The monitoring time points vary from days to weeks (Table 1).

To evaluate the immune response to DC vaccines, immune markers should be monitored at least pre- and postvaccination. Examinations at later time points might reflect how long the effect would be maintained. As Christina et al. reported, to evaluate the immune response, examinations were performed at the time of leukocyte apheresis, after the second and fourth doses of vaccine, and at 4, 5, 6, 9, 12 months after the first dose of vaccine. It was observed that antigen-specific effector $\mathrm{T}$ cell levels were stable in most patients, but the patients with decreasing $\mathrm{T}$ cell levels showed disease progression (53).

\section{FUTURE STUDIES}

In the ovarian cancer microenvironment, tumor immunosuppressive signals induce dendritic cells into a dysfunctional state by affecting the immune function and metabolism of DCs, resulting in difficulty in performing antigen-presenting functions and even promotion of tumor progression. The dendritic cell vaccine provides functional dendritic cells to ovarian cancer patients; thus, it may be a safe and effective immunotherapy for ovarian cancer.

Among the existing preclinical studies and clinical studies, there are huge differences in the preparation process of dendritic cell vaccines, especially the types of tumor-associated antigens used to load dendritic cell vaccines. With the wide application of next-generation sequencing and bioinformatics analysis in various research fields, personalized dendritic cell vaccines have become a hot topic. Because personalized dendritic cell vaccines can activate $\mathrm{T}$ cell cloning targets of patient-specific tumor antigens, they can present a more effective antitumor effect. Although the advantages are obvious, there are still some barriers that need to be overcome for personalized vaccines, such as the complicated preparation process, limited amount of tumor samples from surgery, and difficulty in the accurate selection of tumor antigens. Future studies should pay more attention to these challenges.

Clinical trials in ovarian cancer patients have confirmed the safety of dendritic cell vaccines, but the efficacy of dendritic cell vaccines varies with different preparation methods and trial protocols. Most studies have shown that dendritic cell vaccines can prolong tumor progression-free survival, but the effect on overall survival is not significant. The best evidence will need to be provided by prospective cohort studies with large samples in the future. Although some studies have shown a survival benefit from combination therapy with a vaccine containing dendritic cells, adverse reactions are increased, and this approach should be applied with caution. In addition, although no health economics analysis is available, the cost burden of combination therapy is expected to be greater.

Biomarkers to monitor and predict the efficacy of dendritic cell vaccines will significantly push the research field forward, but none of the biomarkers in current ovarian cancer studies perform well. The ideal biomarker should reflect not only the immune response induced by the vaccine but also the prognosis. Immune cells, cytokines, and chemokines are important parts of the immune response, which are candidate markers. The immune character of tumor microenvironment should also be taken into consideration. According to the current studies, no single indicator can meet the requirements, but a combination of biomarkers may be able to reflect the efficacy of dendritic cell vaccines more comprehensively. Future studies should test different marker groups, making full use of the multilevel information available at the gene, protein, and cell level. 
To sum up, dendritic cell vaccines have been shown to be effective in immunotherapy for ovarian cancer, but there is still untapped potential that needs to be explored by a combination of new technologies, new cohort studies and new biomarkers.

\section{AUTHOR CONTRIBUTIONS}

$\mathrm{XZ}$ was the major contributor in writing the manuscript and design the figures; $\mathrm{TH}$ contributed greatly to build the structure of the review; YL contributed to build the structure of the review and gave suggestions on the manuscript; LC provided

\section{REFERENCES}

1. Siegel RL, Miller KD, Jemal A. Cancer statistics, 2020. CA: Cancer J Clin (2020) 70(1):7-30. doi: 10.3322/caac.21590

2. Gordon AN, Tonda M, Sun S, Rackoff W, Doxil Study I. Long-term survival advantage for women treated with pegylated liposomal doxorubicin compared with topotecan in a phase 3 randomized study of recurrent and refractory epithelial ovarian cancer. Gynecol Oncol (2004) 95(1):1-8. doi: 10.1016/j.ygyno.2004.07.011

3. Rose PG, Blessing JA, Ball HG, Hoffman J, Warshal D, DeGeest K, et al. A phase II study of docetaxel in paclitaxel-resistant ovarian and peritoneal carcinoma: a Gynecologic Oncology Group study. Gynecol Oncol (2003) 88 (2):130-5. doi: 10.1016/S0090-8258(02)00091-4

4. Burger RA, Sill MW, Monk BJ, Greer BE, Sorosky JI. Phase II trial of bevacizumab in persistent or recurrent epithelial ovarian cancer or primary peritoneal cancer: a Gynecologic Oncology Group Study. J Clin Oncol Off J Am Soc Clin Oncol (2007) 25(33):5165-71. doi: 10.1200/JCO.2007.11.5345

5. Stockler MR, Hilpert F, Friedlander M, King MT, Wenzel L, Lee CK, et al. Patient-Reported Outcome Results From the Open-Label Phase III AURELIA Trial Evaluating Bevacizumab-Containing Therapy for Platinum-Resistant Ovarian Cancer. J Clin Oncol (2014) 32(13):1309-+. doi: 10.1200/JCO.2013. 51.4240

6. Kandalaft LE, Odunsi K, Coukos G. Immunotherapy in Ovarian Cancer: Are We There Yet? J Clin Oncol (2019) 37(27):2460-+. doi: 10.1200/JCO.19.00508

7. Kaufman B, Shapira-Frommer R, Schmutzler RK, Audeh MW, Friedlander M, Balmana J, et al. Olaparib Monotherapy in Patients With Advanced Cancer and a Germline BRCA1/2 Mutation. J Clin Oncol (2015) 33(3):244-50. doi: $10.1200 /$ jco.2014.56.2728

8. Coleman RL, Oza AM, Lorusso D, Aghajanian C, Oaknin A, Dean A, et al. Rucaparib maintenance treatment for recurrent ovarian carcinoma after response to platinum therapy (ARIEL3): a randomised, double-blind, placebo-controlled, phase 3 trial. Lancet (2017) 390(10106):1949-61. doi: 10.1016/s0140-6736(17)32440-6

9. Mirza MR, Monk BJ, Herrstedt J, Oza AM, Mahner S, Redondo A, et al. Niraparib Maintenance Therapy in Platinum-Sensitive, Recurrent Ovarian Cancer. New Engl J Med (2016) 375(22):2154-64. doi: 10.1056/NEJMoa1611310

10. Zhang L, Conejo-Garcia JR, Katsaros D, Gimotty PA, Massobrio M, Regnani $\mathrm{G}$, et al. Intratumoral $\mathrm{T}$ cells, recurrence, and survival in epithelial ovarian cancer. New Engl J Med (2003) 348(3):203-13. doi: 10.1056/NEJMoa020177

11. Varga A, Piha-Paul S, Ott PA, Mehnert JM, Berton-Rigaud D, Morosky A, et al. Pembrolizumab in patients with programmed death ligand 1-positive advanced ovarian cancer: Analysis of KEYNOTE-028. Gynecol Oncol (2019) 152(2):243-50. doi: 10.1016/j.ygyno.2018.11.017

12. Webb JR, Milne K, Kroeger DR, Nelson BH. PD-L1 expression is associated with tumor-infiltrating $\mathrm{T}$ cells and favorable prognosis in high-grade serous ovarian cancer. Gynecol Oncol (2016) 141(2):293-302. doi: 10.1016/ j.ygyno.2016.03.008

13. Anguille S, Smits EL, Lion E, van Tendeloo VF, Berneman ZN. Clinical use of dendritic cells for cancer therapy. Lancet Oncol (2014) 15(7):E257-67. doi: 10.1016/S1470-2045(13)70585-0 suggestions on analyzing the clinical trials on dendritic cells; $\mathrm{HL}$ and YW gave suggestions on the structure of the review and the manuscript; HG was the corresponding author of this review, contributed greatly to edit and review the manuscript. All authors contributed to the article and approved the submitted version.

\section{FUNDING}

Supported by the The Capital's Funds for Health Improvement and Research (No.2020-2-4098).

14. Garg AD, Perez MV, Schaaf M, Agostinis P, Zitvogel L, Kroemer G, et al. Trial watch: Dendritic cell-based anticancer immunotherapy. Oncoimmunology (2017) 6(7):17. doi: 10.1080/2162402X.2017.1386829

15. Sprooten J, Ceusters J, Coosemans A, Agostinis P, De Vleeschouwer S, Zitvogel L, et al. Trial watch: dendritic cell vaccination for cancer immunotherapy. Oncoimmunology (2019) 8(11). doi: 10.1080/2162402X.2019.1638212

16. Rahma OE, Ashtar E, Czystowska M, Szajnik ME, Wieckowski E, Bernstein S, et al. A gynecologic oncology group phase II trial of two p53 peptide vaccine approaches: subcutaneous injection and intravenous pulsed dendritic cells in high recurrence risk ovarian cancer patients. Cancer Immunol Immunother (2012) 61(3):373-84. doi: 10.1007/s00262-011-1100-9

17. Tanyi JL, Bobisse S, Ophir E, Tuyaerts S, Roberti A, Genolet R, et al. Personalized cancer vaccine effectively mobilizes antitumor $\mathrm{T}$ cell immunity in ovarian cancer. Sci Trans Med (2018) 10(436):14. doi: 10.1126/ scitranslmed.aao5931

18. Fogg DK, Sibon C, Miled C, Jung S, Aucouturier P, Littman DR, et al. A clonogenic bone marrow progenitor specific for macrophages and dendritic cells. Science (2006) 311(5757):83-7. doi: 10.1126/science.1117729

19. Merad M, Sathe P, Helft J, Miller J, Mortha A. The Dendritic Cell Lineage: Ontogeny and Function of Dendritic Cells and Their Subsets in the Steady State and the Inflamed Setting. In: DR Littman and WM Yokoyama, editors. Annual Review of Immunology, Vol 31. Palo Alto: Annual Reviews (2013). p. 563-604.

20. Hettinger J, Richards DM, Hansson J, Barra MM, Joschko AC, Krijgsveld J, et al. Origin of monocytes and macrophages in a committed progenitor. Nat Immunol (2013) 14(8):821-+. doi: 10.1038/ni.2638

21. Segura E, Amigorena S. Identification of human inflammatory dendritic cells. Oncoimmunology (2013) 2(5):2. doi: 10.4161/onci.23851

22. Fitzgerald KA, Kagan JC. Toll-like Receptors and the Control of Immunity. Cell (2020) 180(6):1044-66. doi: 10.1016/j.cell.2020.02.041

23. Patidar A, Selvaraj S, Sarode A, Chauhan P, Chattopadhyay D, Saha B. DAMP-TLR-cytokine axis dictates the fate of tumor. Cytokine (2018) 104:114-23. doi: 10.1016/j.cyto.2017.10.004

24. Qu C, Edwards EW, Tacke F, Angeli V, Llodrá J, Sanchez-Schmitz G, et al. Role of CCR8 and other chemokine pathways in the migration of monocytederived dendritic cells to lymph nodes. J Exp Med (2004) 200(10):1231-41. doi: $10.1084 /$ jem.20032152

25. Wculek SK, Cueto FJ, Mujal AM, Melero I, Krummel MF, Sancho D. Dendritic cells in cancer immunology and immunotherapy. Nat Rev Immunol (2020) 20(1):7-24. doi: 10.1038/s41577-019-0210-Z

26. Steinman RM. Decisions About Dendritic Cells: Past, Present, and Future. In: WE Paul, editor. Annual Review of Immunology, Vol 30. Palo Alto: Annual Reviews (2012). p. 1-22.

27. Dudek AM, Martin S, Garg AD, Agostinis P. Immature, semi-mature, and fully mature dendritic cells: toward a DC-cancer cells interface that augments anticancer immunity. Front Immunol (2013) 4:14. doi: 10.3389/ fimmu.2013.00438

28. Mempel TR, Henrickson SE, von Andrian UH. T-cell priming by dendritic cells in lymph nodes occurs in three distinct phases. Nature (2004) 427 (6970):154-9. doi: 10.1038/nature02238 
29. Jongbloed SL, Kassianos AJ, McDonald KJ, Clark GJ, Ju XS, Angel CE, et al. Human CD141(+) (BDCA-3)(+) dendritic cells (DCs) represent a unique myeloid DC subset that cross-presents necrotic cell antigens. J Exp Med (2010) 207(6):1247-60. doi: 10.1084/jem.20092140

30. Collin M, Bigley V. Human dendritic cell subsets: an update. Immunology (2018) 154(1):3-20. doi: 10.1111/imm.12888

31. Fucikova J, Palova-Jelinkova L, Bartunkova J, Spisek R. Induction of Tolerance and Immunity by Dendritic Cells: Mechanisms and Clinical Applications. Front Immunol (2019) 10:17. doi: 10.3389/fimmu.2019.02393

32. Hubert M, Gobbini E, Bendriss-Vermare N, Caux C, Valladeau-Guilemond J. Human Tumor-Infiltrating Dendritic Cells: From In Situ Visualization to High-Dimensional Analyses. Cancers (2019) 11(8):25. doi: 10.3390/ cancers 11081082

33. Labidi-Galy SI, Sisirak V, Meeus P, Gobert M, Treilleux I, Bajard A, et al. Quantitative and Functional Alterations of Plasmacytoid Dendritic Cells Contribute to Immune Tolerance in Ovarian Cancer. Cancer Res (2011) 71 (16):5423-34. doi: 10.1158/0008-5472.CAN-11-0367

34. Labidi-Galy SI, Treilleux I, Goddard-Leon S, Combes JD, Blay JY, RayCoquard I, et al. Plasmacytoid dendritic cells infiltrating ovarian cancer are associated with poor prognosis. Oncoimmunology (2012) 1(3):379-81. doi: 10.4161/onci.18801

35. Mastelic-Gavillet B, Sarivalasis A, Lozano LE, Wyss T, Inoges S, de Vries IJM, et al. Quantitative and qualitative impairments in dendritic cell subsets of patients with ovarian or prostate cancer. Eur J Cancer (Oxford Engl 1990) (2020) 135:173-82. doi: 10.1016/j.ejca.2020.04.036

36. Rossi JF, Ceballos P, Lu ZY. Immune precision medicine for cancer: a novel insight based on the efficiency of immune effector cells. Cancer Commun (2019) 39:16. doi: 10.1186/s40880-019-0379-3

37. Harimoto H, Shimizu M, Nakagawa Y, Nakatsuka K, Wakabayashi A, Sakamoto C, et al. Inactivation of tumor-specific CD8(+) CTLs by tumorinfiltrating tolerogenic dendritic cells. Immunol Cell Biol (2013) 91(9):545-55. doi: $10.1038 /$ icb. 2013.38

38. Scarlett UK, Rutkowski MR, Rauwerdink AM, Fields J, Escovar-Fadul X, Baird $\mathrm{J}$, et al. Ovarian cancer progression is controlled by phenotypic changes in dendritic cells. J Exp Med (2012) 209(3):495-506. doi: 10.1084/jem.20111413

39. Flies DB, Higuchi T, Harris JC, Jha V, Gimotty PA, Adams SF. Immune checkpoint blockade reveals the stimulatory capacity of tumor-associated CD103 (+) dendritic cells in late-stage ovarian cancer. Oncoimmunology (2016) 5(8): el185583. doi: 10.1080/2162402X.2016.1185583

40. Conrad C, Gregorio J, Wang YH, Ito T, Meller S, Hanabuchi S, et al. Plasmacytoid Dendritic Cells Promote Immunosuppression in Ovarian Cancer via ICOS Costimulation of Foxp3(+) T-Regulatory Cells. Cancer Res (2012) 72(20):5240-9. doi: 10.1158/0008-5472.CAN-12-2271

41. Munn DH, Mellor AL. IDO in the Tumor Microenvironment: Inflammation, Counter-Regulation, and Tolerance. Trends Immunol (2016) 37(3):193-207. doi: 10.1016/j.it.2016.01.002

42. Beatty GL, O'Dwyer PJ, Clark J, Shi JG, Bowman KJ, Scherle PA, et al. First-inHuman Phase I Study of the Oral Inhibitor of Indoleamine 2,3-Dioxygenase-1 Epacadostat (INCB024360) in Patients with Advanced Solid Malignancies. Clin Cancer Res (2017) 23(13):3269-76. doi: 10.1158/1078-0432.CCR-162272

43. Cubillos-Ruiz JR, Silberman PC, Rutkowski MR, Chopra S, Perales-Puchalt A, Song M, et al. ER Stress Sensor XBP1 Controls Anti-tumor Immunity by Disrupting Dendritic Cell Homeostasis. Cell (2015) 161(7):1527-38. doi: 10.1016/j.cell.2015.05.025

44. Liefers-Visser JAL, Meijering RAM, Reyners AKL, van der Zee AGJ, de Jong S. IGF system targeted therapy: Therapeutic opportunities for ovarian cancer. Cancer Treat Rev (2017) 60:90-9. doi: 10.1016/j.ctrv.2017.08.012

45. Huang C-T, Chang M-C, Chen Y-L, Chen T-C, Chen C-A, Cheng W-F. Insulin-like growth factors inhibit dendritic cell-mediated anti-tumor immunity through regulating ERK1/2 phosphorylation and p38 dephosphorylation. Cancer Lett (2015) 359(1):117-26. doi: 10.1016/j.canlet. 2015.01.007

46. Somri-Gannam L, Meisel-Sharon S, Hantisteanu S, Groisman G, Limonad O, Hallak M, et al. IGF1R Axis Inhibition Restores Dendritic Cell Antitumor Response in Ovarian Cancer. Trans Oncol (2020) 13(8):100790-0. doi: 10.1016/ j.tranon.2020.100790
47. Dhodapkar MV, Sznol M, Zhao B, Wang D, Carvajal RD, Keohan ML, et al. Induction of Antigen-Specific Immunity with a Vaccine Targeting NY-ESO-1 to the Dendritic Cell Receptor DEC-205. Sci Trans Med (2014) 6(232). doi: 10.1126/scitranslmed.3008068

48. Romano E, Rossi M, Ratzinger G, de Cos MA, Chung DJ, Panageas KS, et al. Peptide-Loaded Langerhans Cells, Despite Increased IL15 Secretion and TCell Activation In Vitro, Elicit Antitumor T-Cell Responses Comparable to Peptide-Loaded Monocyte-Derived Dendritic Cells In Vivo. Clin Cancer Res (2011) 17(7):1984-97. doi: 10.1158/1078-0432.CCR-10-3421

49. Zhou Y, Slone N, Chrisikos TT, Kyrysyuk O, Babcock RL, Medik YB, et al. Vaccine efficacy against primary and metastatic cancer with in vitro-generated CD103+ conventional dendritic cells. J Immunother Cancer (2020) 8(1). doi: 10.1136/jitc-2019-000474

50. Vazquez J, Chavarria M, Lopez GE, Felder MA, Kapur A, Romo Chavez A, et al. Identification of unique clusters of $\mathrm{T}$, dendritic, and innate lymphoid cells in the peritoneal fluid of ovarian cancer patients. Am J Reprod Immunol (2020) 84(3). doi: 10.1111/aji.13284

51. Zhang W, Lu X, Cui P, Piao C, Xiao M, Liu X, et al. Phase I/II clinical trial of a Wilms' tumor 1-targeted dendritic cell vaccination-based immunotherapy in patients with advanced cancer. Cancer Immunol Immunother (2019) 68 (1):121-30. doi: 10.1007/s00262-018-2257-2

52. Brossart P, Wirths S, Stuhler G, Reichardt VL, Kanz L, Brugger W. Induction of cytotoxic T-lymphocyte responses in vivo after vaccinations with peptidepulsed dendritic cells. Blood (2000) 96(9):3102-8. doi: 10.1182/blood. V96.9.3102.h8003102_3102_3108

53. Chu CS, Boyer J, Schullery DS, Gimotty PA, Gamerman V, Bender J, et al. Phase I/II randomized trial of dendritic cell vaccination with or without cyclophosphamide for consolidation therapy of advanced ovarian cancer in first or second remission. Cancer Immunol Immunother (2012) 61(5):629-41. doi: 10.1007/s00262-011-1081-8

54. Mitchell PL, Quinn MA, Grant PT, Allen DG, Jobling TW, White SC, et al. A phase 2, single-arm study of an autologous dendritic cell treatment against mucin 1 in patients with advanced epithelial ovarian cancer. J Immunother Cancer (2014) 2:16. doi: 10.1186/2051-1426-2-16

55. Kobayashi M, Chiba A, Izawa H, Yanagida E, Okamoto M, Shimodaira S, et al The feasibility and clinical effects of dendritic cell-based immunotherapy targeting synthesized peptides for recurrent ovarian cancer. J Ovarian Res (2014) 7:9. doi: 10.1186/1757-2215-7-48

56. Coosemans A, Vanderstraeten A, Tuyaerts S, Verschuere T, Moerman P, Berneman Z, et al. Immunological Response after WT1 mRNA-loaded Dendritic Cell Immunotherapy in Ovarian Carcinoma and Carcinosarcoma. Anticancer Res (2013) 33(9):3855-9.

57. Morisaki T, Hikichi T, Onishi $\mathrm{H}$, Morisaki $\mathrm{T}$, Kubo M, Hirano $\mathrm{T}$, et al. Intranodal Administration of Neoantigen Peptide-loaded Dendritic Cell Vaccine Elicits Epitope-specific T Cell Responses and Clinical Effects in a Patient with Chemorefractory Ovarian Cancer with Malignant Ascites. Immunol Invest (2020) 13:1-18. doi: 10.1080/08820139.2020.1778721

58. Chiang CLL, Kandalaft LE, Tanyi J, Hagemann AR, Motz GT, Svoronos N, et al. A Dendritic Cell Vaccine Pulsed with Autologous Hypochlorous AcidOxidized Ovarian Cancer Lysate Primes Effective Broad Antitumor Immunity: From Bench to Bedside. Clin Cancer Res (2013) 19(17):4801-15. doi: 10.1158/1078-0432.CCR-13-1185

59. Kandalaft LE, Powell DJ, Chiang CL, Tanyi J, Kim S, Bosch M, et al. Autologous lysate-pulsed dendritic cell vaccination followed by adoptive transfer of vaccine-primed ex vivo co-stimulated $\mathrm{T}$ cells in recurrent ovarian cancer. Oncoimmunology (2013) 2(1):10. doi: 10.4161/onci.22664

60. Bapsy PP, Sharan B, Kumar C, Das RP, Rangarajan B, Jain M, et al. Open-label, multi-center, non-randomized, single-arm study to evaluate the safety and efficacy of dendritic cell immunotherapy in patients with refractory solid malignancies, on supportive care. Cytotherapy (2014) 16(2):234-44. doi: 10.1016/j.jcyt.2013.11.013

61. Hernando JJ, Park TW, Fischer HP, Zivanovic O, Braun M, Polcher M, et al. Vaccination with autologous tumour antigen-pulsed dendritic cells in advanced gynaecological malignancies: clinical and immunological evaluation of a phase I trial. Cancer Immunol Immunother (2002) 51(1):4552. doi: 10.1007/s00262-001-0255-1

62. Baek S, Kim Y-M, Kim S-B, Kim C-S, Kwon S-W, Kim Y, et al. Therapeutic DC vaccination with IL-2 as a consolidation therapy for ovarian cancer 
patients: a phase I/II trial. Cell Mol Immunol (2015) 12(1). doi: 10.1038/ cmi.2014.40

63. Fisk B, Blevins TL, Wharton JT, Ioannides CG. Identification Of An Immunodominant Peptide Of Her-2/Neu Protooncogene Recognized By Ovarian Tumor-Specific Cytotoxic T-Lymphocyte Lines. J Exp Med (1995) 181(6):2109-17. doi: 10.1084/jem.181.6.2109

64. Peoples GE, Goedegebuure PS, Smith R, Linehan DC, Yoshino I, Eberlein TJ. Breast And Ovarian Cancer-Specific Cytotoxic T-Lymphocytes Recognize The Same Her2/Neu-Derived Peptide. Proc Natl Acad Sci USA (1995) 92(2):432-6. doi: $10.1073 /$ pnas.92.2.432

65. Peethambaram PP, Melisko ME, Rinn KJ, Alberts SR, Provost NM, Jones LA, et al. A Phase I Trial of Immunotherapy with Lapuleucel-T (APC8024) in Patients with Refractory Metastatic Tumors that Express HER-2/neu. Clin Cancer Res (2009) 15(18):5937-44. doi: 10.1158/1078-0432.CCR-08-3282

66. Chapuis AG, Ragnarsson GB, Nguyen HN, Chaney CN, Pufnock JS, Schmitt TM, et al. Transferred WT1-Reactive CD8(+) T Cells Can Mediate Antileukemic Activity and Persist in Post-Transplant Patients. Sci Trans Med (2013) 5(174). doi: 10.1126/scitranslmed.3004916

67. Wang L, Ma J, Liu F, Yu Q, Chu G, Perkins AC, et al. Expression of MUC1 in primary and metastatic human epithelial ovarian cancer and its therapeutic significance. Gynecol Oncol (2007) 105(3):695-702. doi: 10.1016/j.ygyno.2007.02.004

68. Dionisi M, De Archangelis C, Battisti F, Koshkaki HR, Belleudi F, Zizzari IG, et al. Tumor-Derived Microvesicles Enhance Cross-Processing Ability of Clinical Grade Dendritic Cells. Front Immunol (2018) 9:13. doi: 10.3389/ fimmu.2018.02481

69. Loveland BE, Zhao A, White S, Gan H, Hamilton K, Xing PX, et al. MannanMUC1 - Pulsed dendritic cell immunotherapy: A phase I trial in patients with adenocarcinoma. Clin Cancer Res (2006) 12(3):869-77. doi: 10.1158/10780432.CCR-05-1574

70. Hernando JJ, Park TW, Fischer HP, Zivanovic O, Braun M, Polcher M, et al. Vaccination with dendritic cells transfected with mRNA-encoded folatereceptor-alpha for relapsed metastatic ovarian cancer. Lancet Oncol (2007) 8(5):451-4. doi: 10.1016/S1470-2045(07)70142-0

71. Homma S, Sagawa Y, Ito M, Ohno T, Toda G. Cancer immunotherapy using dendritic/tumour-fusion vaccine induces elevation of serum anti-nuclear antibody with better clinical responses. Clin Exp Immunol (2006) 144 (1):41-7. doi: 10.1111/j.1365-2249.2006.03029.x

72. Bernal SD, Ona ET, Riego-Javier A, De Villa R, Cristal-Luna GR, Laguatan JB, et al. Anticancer immune reactivity and long-term survival after treatment of metastatic ovarian cancer with dendritic cells. Oncol Lett (2012) 3(1):66-74. doi: $10.3892 / 01.2011 .424$

73. Shimizu K, Thomas EK, Giedlin M, Mule JJ. Enhancement of tumor lysateand peptide-pulsed dendritic cell-based vaccines by the addition of foreign helper protein. Cancer Res (2001) 61(6):2618-24.

74. Mastelic-Gavillet B, Balint K, Boudousquie C, Gannon PO, Kandalaft LE. Personalized Dendritic Cell Vaccines-Recent Breakthroughs and Encouraging Clinical Results. Front Immunol (2019) 10. doi: 10.3389/fimmu.2019.00766

75. Carreno BM, Magrini V, Becker-Hapak M, Kaabinejadian S, Hundal J, Petti AA, et al. A dendritic cell vaccine increases the breadth and diversity of melanoma neoantigen-specific T cells. Science (2015) 348(6236):803-8. doi: $10.1126 /$ science.aaa3828

76. Sahin U, Derhovanessian E, Miller M, Kloke BP, Simon P, Lower M, et al. Personalized RNA mutanome vaccines mobilize poly-specific therapeutic immunity against cancer. Nature (2017) 547(7662):222-+. doi: 10.1038/ nature23003

77. Wang QT, Nie Y, Sun SN, Lin T, Han RJ, Jiang J, et al. Tumor-associated antigen-based personalized dendritic cell vaccine in solid tumor patients. Cancer Immunol Immunother (2020), 13. doi: 10.1007/s00262-020-02496-w

78. Sarivalasis A, Boudousquie C, Balint K, Stevenson BJ, Gannon PO, Iancu EM, et al. A Phase I/II trial comparing autologous dendritic cell vaccine pulsed either with personalized peptides (PEP-DC) or with tumor lysate (OC-DC) in patients with advanced high-grade ovarian serous carcinoma. J Trans Med (2019) 17(1):10. doi: 10.1186/s12967-019-02133-w

79. Chiang CL, Maier DA, Kandalaft LE, Brennan AL, Lanitis E, Ye Q, et al. Optimizing parameters for clinical-scale production of high IL-12 secreting dendritic cells pulsed with oxidized whole tumor cell lysate. $J$ Transl Med (2011) 9:198. doi: 10.1186/1479-5876-9-198

80. Truxova I, Hensler M, Skapa P, Halaska MJ, Laco J, Ryska A, et al. Rationale for the Combination of Dendritic Cell-Based Vaccination Approaches With Chemotherapy Agents. In: L Galluzzi, editor. International Review of Cell and Molecular Biology, Vol 330. San Diego: Elsevier Academic Press Inc (2017). p. 115-56.

81. Pfannenstiel LW, Lam SSK, Emens LA, Jaffee EM, Armstrong TD. Paclitaxel enhances early dendritic cell maturation and function through TLR4 signaling in mice. Cell Immunol (2010) 263(1):79-87. doi: 10.1016/j.cellimm. 2010.03.001

82. Huijts CM, Lougheed SM, Bodalal Z, van Herpen CM, Hamberg P, Tascilar $\mathrm{M}$, et al. The effect of everolimus and low-dose cyclophosphamide on immune cell subsets in patients with metastatic renal cell carcinoma: results from a phase I clinical trial. Cancer Immunol Immunother (2019) 68(3):503-15. doi: 10.1007/s00262-018-2288-8

83. Cai DL, Li JM, Liu DF, Hong SJ, Qiao Q, Sun QL, et al. Tumor-expressed B7$\mathrm{H} 3$ mediates the inhibition of antitumor T-cell functions in ovarian cancer insensitive to PD-1 blockade therapy. Cell Mol Immunol (2020) 17(3):227-36. doi: 10.1038/s41423-019-0305-2

84. Mussai F, De Santo C, Cerundolo V. Interaction Between Invariant NKT Cells and Myeloid-derived Suppressor Cells in Cancer Patients: Evidence and Therapeutic Opportunities. J Immunother (2012) 35(6):449-59. doi: 10.1097/CJI.0b013e31825be926

85. Verdijk P, Aarntzen E, Lesterhuis WJ, Boullart ACI, Kok E, van Rossum MM, et al. Limited Amounts of Dendritic Cells Migrate into the T-Cell Area of Lymph Nodes but Have High Immune Activating Potential in Melanoma Patients. Clin Cancer Res (2009) 15(7):2531-40. doi: 10.1158/1078-0432.CCR-08-2729

86. Kandalaft LE, Chiang CL, Tanyi J, Motz G, Balint K, Mick R, et al. A Phase I vaccine trial using dendritic cells pulsed with autologous oxidized lysate for recurrent ovarian cancer. J Trans Med (2013) 11:14. doi: 10.1186/1479-587611-149

87. Hsu MS, Sedighim S, Wang TN, Antonios JP, Everson RG, Tucker AM, et al. TCR Sequencing Can Identify and Track Glioma-Infiltrating T Cells after DC Vaccination. Cancer Immunol Res (2016) 4(5):412-8. doi: 10.1158/23266066.CIR-15-0240

88. Jan C-I, Tsai W-C, Harn H-J, Shyu W-C, Liu M-C, Lu H-M, et al. Predictors of Response to Autologous Dendritic Cell Therapy in Glioblastoma Multiforme. Front Immunol (2018) 9. doi: 10.3389/fimmu.2018.00727

89. Yao Y, Luo F, Tang C, Chen D, Qin Z, Hua W, et al. Molecular subgroups and B7-H4 expression levels predict responses to dendritic cell vaccines in glioblastoma: an exploratory randomized phase II clinical trial. Cancer Immunol Immunother (2018) 67(11):1777-88. doi: 10.1007/s00262-018-2232-y

90. Alvero AB, Hanlon D, Pitruzzello M, Filler R, Robinson E, Sobolev O, et al. Transimmunization restores immune surveillance and prevents recurrence in a syngeneic mouse model of ovarian cancer. Oncoimmunology (2020) 9 (1):1758869. doi: 10.1080/2162402X.2020.1758869

91. Sautes-Fridman C, Petitprez F, Calderaro J, Fridman WH. Tertiary lymphoid structures in the era of cancer immunotherapy. Nat Rev Cancer (2019) 19 (6):307-25. doi: 10.1038/s41568-019-0144-6

92. Truxova I, Kasikova L, Hensler M, Skapa P, Laco J, Pecen L, et al. Mature dendritic cells correlate with favorable immune infiltrate and improved prognosis in ovarian carcinoma patients. J Immunother Cancer (2018) 6:13. doi: $10.1186 / s 40425-018-0446-3$

Conflict of Interest: The authors declare that the research was conducted in the absence of any commercial or financial relationships that could be construed as a potential conflict of interest.

Copyright (c) 2021 Zhang, He, Li, Chen, Liu, Wu and Guo. This is an open-access article distributed under the terms of the Creative Commons Attribution License (CC BY). The use, distribution or reproduction in other forums is permitted, provided the original author(s) and the copyright owner(s) are credited and that the original publication in this journal is cited, in accordance with accepted academic practice. No use, distribution or reproduction is permitted which does not comply with these terms. 